${ }^{1}$ Тернопільський начіональний економічний університет, м. Тернопіль, Украӥна; ${ }^{2}$ Національний університет "Львівська політехніка", м. Львів, Україна.

\title{
ВИКОРИСТАННЯ ІНГІБІТОРНИХ МЕРЕЖ ПЕТРІ ДЛЯ ПОБУДОВИ АВТОМАТИЗОВАНОЇ СИСТЕМИ ОБЛІКУ ПАСАЖИРОПОТОКУ ГРОМАДСЬКОГО ТРАНСПОРТУ "РОЗУМНОГО" МІСТА
}

Визначено загальний тренд політичних ініціатив Європейського Союзу щодо модернізації та підвищення ефективності всіх сфер діяльності сучасних мегаполісів. Проведено аналіз базових принципів концепції "розумного" міста, спрямованих на оптимізацію транспортної системи сучасних міст. Доведено важливість дослідження пасажиропотоків громадського транспорту, результати якого можна використати для розроблення комплексу дій із вдосконалення організації наявних перевезень пасажирів на діючих маршрутах, а також для реорганізації транспортної мережі міста загалом. Здійснено аналіз засобів моделювання складних дискретних систем для побудови та дослідження моделей автоматизованої системи обліку пасажирів у громадському транспорті "розумного" міста. Доведено, що використання інгібіторних мереж Петрі забезпечує ефективніший процес моделювання, адже для побудови моделі на їх основі потрібно використати менше елементів мережі, що призводить до генерації чіткішого, зрозумілішого та легшого для аналізу графу досяжності станів мережі Петрі. Розроблено модель контролера збирання даних про пасажиропотік автоматизованої системи на основі інгібіторних мереж Петрі. Використання інгібіторних мереж Петрі дає змогу спростити структуру моделі, що призводить до зменшення обчислювальних ресурсів, які необхідні для реалізації моделі засобами персонального комп'ютера.

Ключові слова: модель; контролер; інгібіторні дуги; транспортна система міста; дослідження моделі.

Вступ. Раціональніше використання обмежених ресурсів нашої планети та прагнення людства до ефективнішого використання часу сьогодні можуть бути досягнуті завдяки використанню інформаційно-комунікаційних технологій (IКT). Зокрема у містах, де концентрація людей $є$ дуже високою, ІКТ дають змогу досягати істотної економії інвестицій у міську інфраструктуру (Zhuhadar, et al., 2017).

У цьому сенсі місто може мати величезні переваги завдяки створенню оперативних систем, здатних збирати, аналізувати та опрацьовувати потоки даних, отриманих в реальному часі від мережі давачів та іншого обладнання. Подібне обладнання призначене для різноманітних цілей та застосувань, метою яких є забезпечення ефективнішого використання всіх послуг, які надаються муніципалітетом через операторів і $є$ важливими для життя громадян та організацій (Kupriyanovsky, et al., 2016).

У цьому контексті $\mathrm{CC}(\mathrm{EU})$ розпочав ініціативу в 2011 р., коли в рамках нової політичної основи "Промислова ініціатива "розумних" міст та громад" ("Smart Cities \& Communities Industrial Initiative") було представлено стратегії майбутніх інвестицій в технології 3 низьким вмістом вуглецю, 3 конкретними кліматичними та енергетичними цілями для досягнення до 2020 р., а також планом дій зі скорочення викидів парникових газів до 2050 р. (Gentile \& Nökel, 2016).

"Розумне" місто сприяє інвестиціям у різні сфери діяльності міст, такі як: транспорт, логістика, безпека, безпека води, каналізація, опалення, енергія, охорона здоров'я, школа, туризм і т. ін. Державне управління на різних рівнях має бути здатним здійснювати моніторинг, надання та контроль послуг для цих критичних напрямів (Byun, et al., 2016).

Громадський транспорт почав відігравати важливу роль у концепції "розумного" міста. Дані, взяті безпосередньо з послуг громадського транспорту (наприклад, пасажиропотік, електронні квитки, відео, місцезнаходження транспортного засобу тощо), можуть бути інтегровані 3 великою кількістю приватних моніторингових та інформаційних систем транспорту, як для реального часу, так $\mathrm{i}$ для офлайнової програми. Становлення систем зв'язку транспортний-засіб - транспортний-засіб (vehicle-to-vehicle), інфраструктура - транспортний-засіб (infrastructure-to-vehicle) та користувач - транспортний-засіб (скорочено V2X) дають змогу покращити надання транспор-

\section{Інформація про авторів:}

Борейко Олег Юрійович, аспірант кафедри комп'ютерної інженерії. Email: boreiko.work@gmail.com

Теслюк Василь Миколайович, д-р техн. наук, професор, завідувач кафедри інформаційних систем і технологій, інституту підприємництва та перспективних технологій. Email: vasyl.m.teslyuk@Ipnu.ua

Цитування за Дсту: Борейко О. Ю., Теслюк В. М. Використання інгібіторних мереж Петрі для побудови автоматизованої системи обліку пасажиропотоку громадського транспорту "Розумного" міста. Науковий вісник НЛТУ України. 2018, т. 28, № 2. C. 150-154.

Citation APA: Boreiko, O. Yu., \& Teslyuk, V. M. (2018). Use of Petri Nets with Inhibitor Arcs to Construct the Automated System for Registering Passenger Flow in Public Transport of a Smart City. Scientific Bulletin of UNFU, 28(2), 150-154. https://doi.org/10.15421/40280228 
тних послуг та збільшити ефективність використання потужності транспортних систем (Nowicka, 2014).

Громадський транспорт забезпечує значно економніше використання проїжджої частини доріг під час обслуговування пасажиропотоків, а отже, покращує загальну продуктивність вулично-дорожньої мережі (Воreiko, et al., 2017).

Дослідження пасажиропотоків дає змогу виявити основні закономірності їх коливання для використання отриманих результатів у плануванні та організації перевезень. Тобто характер зміни пасажиропотоків на маршрутах і загалом для конкретного населеного пункту підпорядковується певній закономірності, тому систематичне виявлення розподілу пасажиропотоків за часом, довжиною маршрутів і напрямками є однією 3 основних задач служб експлуатації транспортних підприємств.

Пасажиропотоки характеризують навантаження на транспортну мережу за напрямками переміщень у певний період часу (годину, добу, місяць). Результати дослідження пасажиропотоків використовують як для вдосконалення організації перевезень пасажирів на діючих маршрутах, так і для реорганізації транспортної мережі загалом (Lebedeva, 2014).

За матеріалами дослідження можна встановити основні техніко-експлуатаційні показники роботи автобусів: обсяг перевезень, пасажирообіг, середню дальність поїздки пасажирів, наповненість автобусів і їх кількість на маршрутах, час рейсу i кількість робочих змін, швидкість, інтервали і частоту руху, пробіг за час зміни. Ці дані можуть бути підставою для вдосконалення як системи маршрутів загалом, так і організації руху і роботи автобусів за кожним конкретним маршрутом (Boreiko \& Teslyuk, 2017a).

Важливим етапом дослідження пасажиропотоків громадського транспорту i, відповідно, актуальною задачею на шляху вдосконалення транспортної системи "розумного" міста є побудова автоматизованої системи обліку пасажирів.

Матеріали та методи дослідження. Одним з початкових етапів розроблення систем є побудова моделей та дослідження параметрів проектованого виробу на системному рівні. Особливістю цього рівня є використання структурних моделей, які грунтуються на теорії мереж Петрі, систем масового обслуговування та ін. Мережа Петрі - це орієнтований граф, що містить позиції (вершини), що визначають умови, наявні в системі, і переходи, що відображають пов'язані з цими умовами дії (Boreiko \& Teslyuk, 2017b).

У загальному випадку, модель на основі мереж Петрі можна описати виразом

$$
N=\left\{S, T, F, M_{0}\right\},
$$

де: $S=\left\{S_{1}, S_{2}, \ldots S_{a}\right\}-$ множина позицій (станів); $T=$ $\left\{T_{1}, T_{2}, \ldots T_{b}\right\}$ - множина переходів; $F-$ множина дуг, яка містить дві підмножини вхідних $F_{i n}=\left\{F_{i n, 1}, F_{i n, 2}, \ldots, F_{i n, l}\right\}$

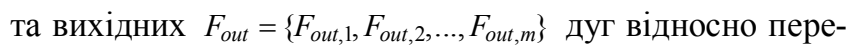
ходу; $M_{0}-$ множина, яка задає початкове маркування мережі Петрі; $a, b-$ кількість позицій і переходів; $l+m$ $=n-$ кількість дуг.

Мережі Петрі функціонують безперервно у часі. Динаміка функціонування визначається правилами спрацьовування переходів. Зміна стану мережі пов'яза- на 3 механізмом зміни маркувань позицій. У випадку простої мережі Петрі:

- спрацьовує тільки активний перехід, тобто такий, у всіх вхідних позиціях якого є мітки;

- спрацьовування переходу настає після його активації, причому якщо виникає конфлікт - одночасна активація кількох переходів, що мають спільні вхідні вершини, то спрацьовує рівноймовірно тільки один з конфліктних переходів;

- внаслідок спрацьовування переходу кількість міток у кожній вхідній позиції зменшується на одиницю, а кількість міток у всіх вихідних позиціях збільшується на одиницю.

Приклад моделювання елементарного циклу обслуговування засобами простих мереж Петрі представлено на рис. 1.

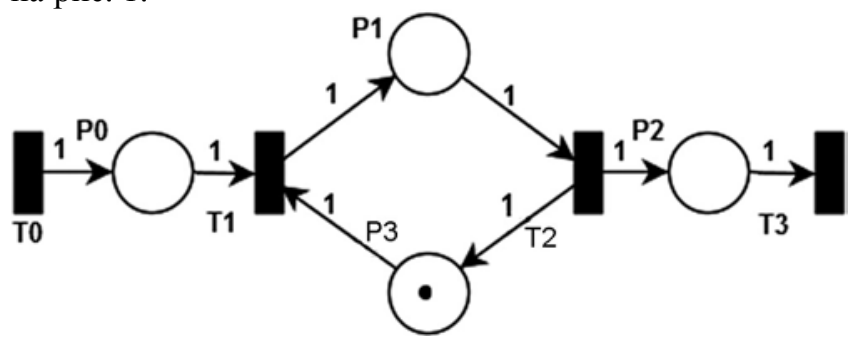

Рис. 1. Черга на обслуговування на основі простих мереж Петрі

Особливим різновидом мереж Петрі є інгібіторні мережі, які на додаток до звичайних дуг графу мережі містять "забороняючі", так звані інгібіторні дуги (Kotov, 1984). Така дуга забороняє активацію переходу при наявності достатньої кількості міток у вхідних вершинах звичайних дуг доти, поки в її вхідній вершині $є$ мітки.

Модель на основі інгібіторних мереж Петрі також описують загальним виразом (1), за тією лиш відмінністю, що інгібіторна мережа включає додаткову підмножину дуг. Цю підмножину становлять інгібіторні дуги відносно кожного переходу

$$
F_{n o t}=\left\{F_{n o t, 1}, F_{\text {not }, 2}, \ldots, F_{\text {not }, k}\right\} .
$$

Відповідно, загальна кількість всіх дуг інгібіторної мережі Петрі може бути представлена виразом

$$
l+m+k=n,
$$

де: $l$ - кількість вхідних дуг; $m$ - кількість вихідних дуг; $k$ - кількість інгібіторних дуг мережі.

У фрагменті мережі Петрі, наведеному на рис. 2, дуга забороняє запуск переходу Т0 за наявності мітки в позиції Р0. Приклад реалізації найпростішого циклу обслуговування $з$ використанням інгібіторної мережі Петpi наведено на рис. 3. Тут перехід Т1 за наявності мітки в позиції P1 буде "заборонений", незважаючи на наявність мітки у вершині Р0 доти, поки мітка не покине P1 через перехід Т2, що еквівалентно завершенню чергового обслуговування.

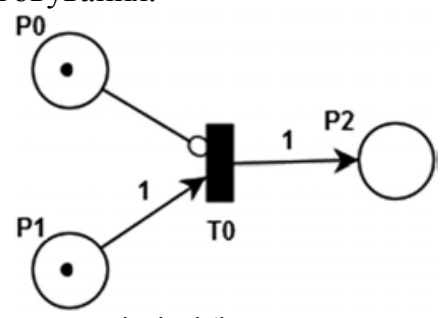

Pис. 2. Фрагмент мережі з інгібіторною дугою

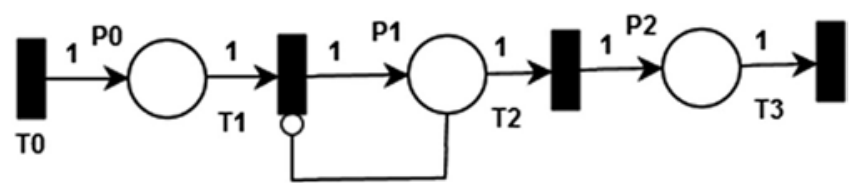

Рис. 3. Черга на обслуговування на основі інгібіторних мереж Петрі 
Як видно з наведених вище прикладів, використання інгібіторних мереж Петрі навіть для моделювання роботи елементарних обчислювальних процесів дає змогу зменшити кількість елементів, необхідних для побудови мережі. Зокрема проста мережа Петрі містить 16 елементів (4 позиції, 4 переходи і 8 дуг), а інгібіторна 14 елементів (3 позиції, 4 переходи і 7 дуг). При чому функціональні можливості обох мереж еквівалентні.

Використання інгібіторних мереж для побудови моделі автоматизованої системи обліку пасажиропотоку громадського транспорту "розумного" міста дає змогу істотно зменшити кількість елементів мереж, а як наслідок - спростити та зробити ефективнішим весь процес розроблення та дослідження моделей. Приклад побудови моделі контролера збирання даних автоматизованої системи засобами простих (зліва) та інгібіторних (справа) мереж Петрі наведено на рис. 4.

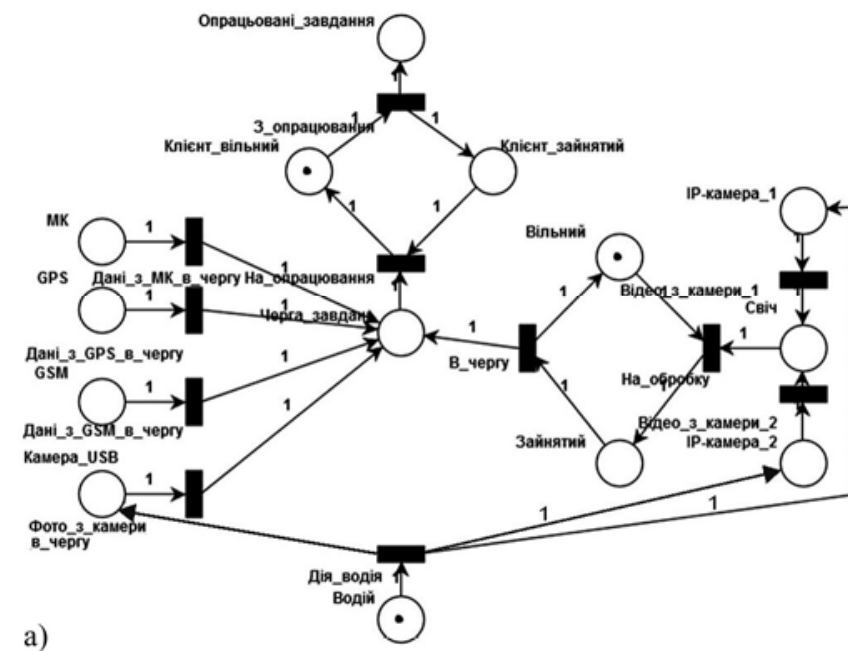

Дослідження побудованих моделей дає змогу зробити висновок про те, що використання інгібіторних мереж Петрі забезпечує ефективніший процес моделювання, адже для побудови моделі контролера збору даних на основі інгібіторних мереж необхідно використати на 9,5\% менше елементів мережі.

Як наслідок, зменшення кількості елементів призводить до генерації чіткішого, зрозумілішого та легшого для аналізу графу досяжності станів мережі Петрі. Порівняно із графом, побудованим для моделі контролера на основі простих мереж Петрі для часткових випадків моделювання, граф для моделі на базі інгібіторних мереж має на 25,5\% менше станів i, як наслідок, є читабельнішим. Описані графи досяжності станів відповідних мереж зображено на рис. 5.

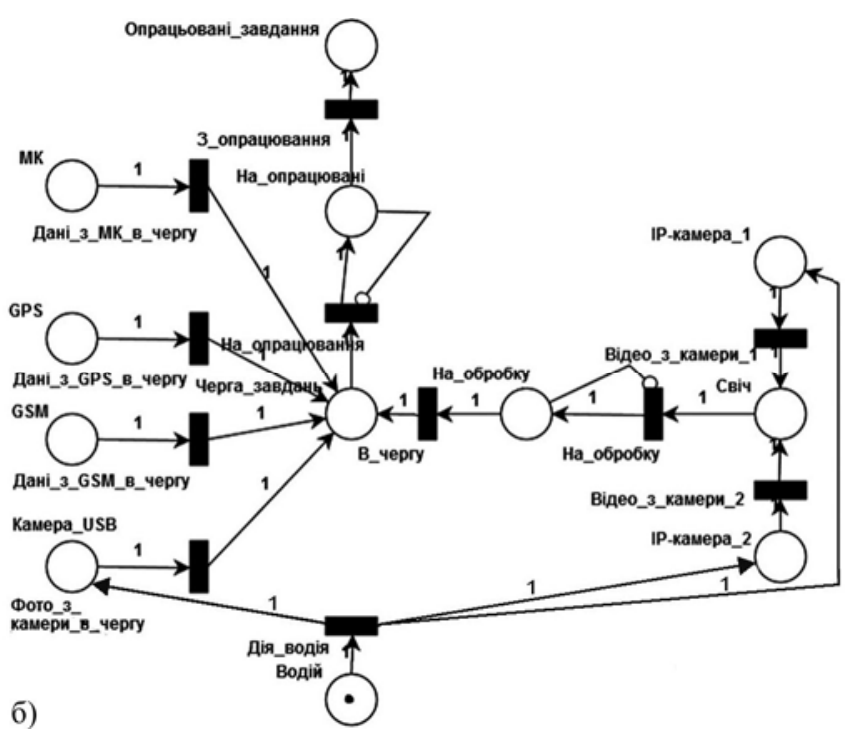

б)

Рис. 4. Структурна модель контролера на основі простих (зліва) та інгібіторних (справа) мереж Петрі

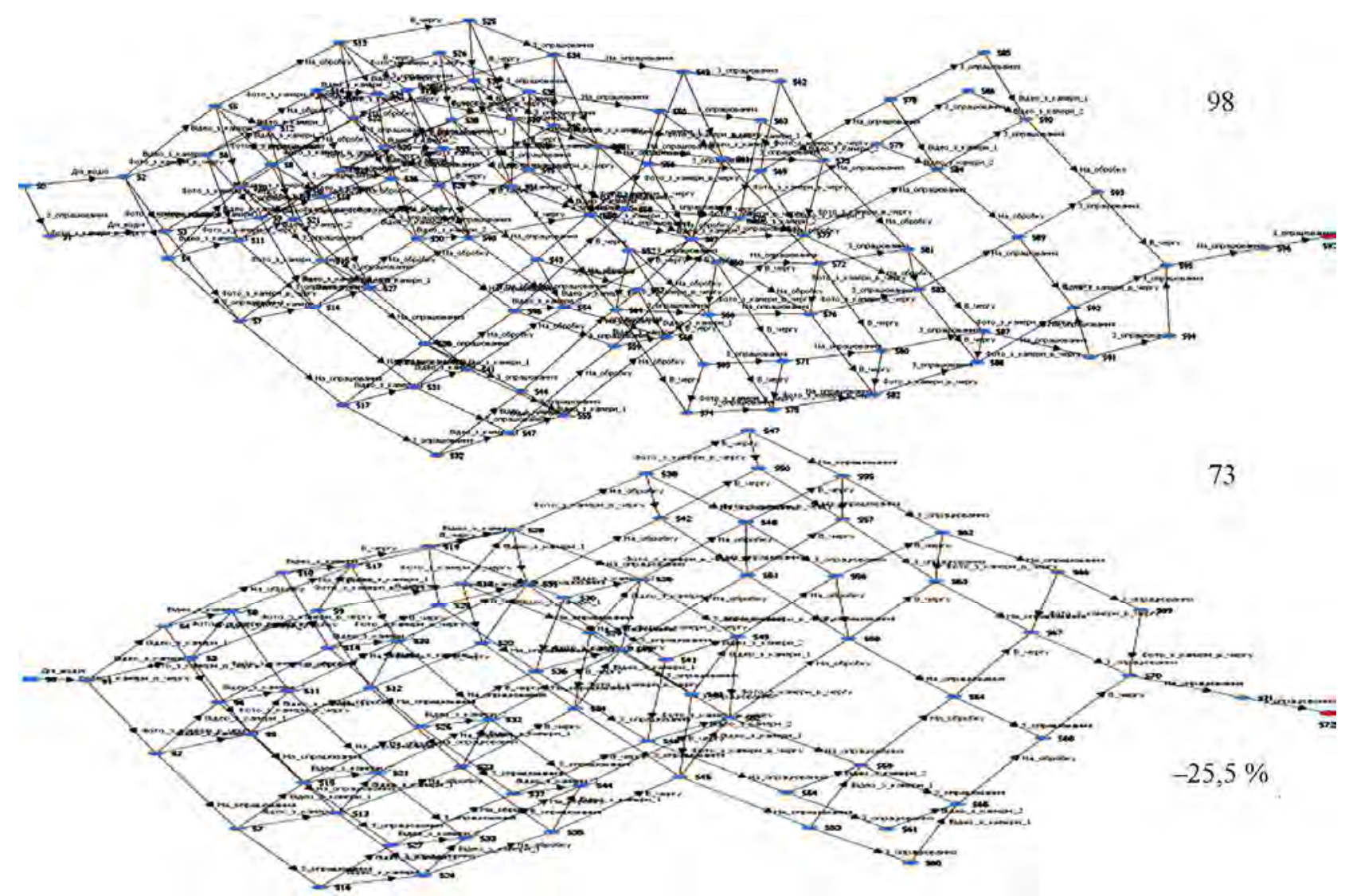

Рис. 5. Графи досяжності станів для моделі контролера на основі простих (зверху) та інгібіторних (знизу) мереж Петрі 
Граф, побудований засобами інгібіторних мереж Петрі, описує на 25 станів менше і є зручнішим для аналізу та подальшого дослідження мережі.

Результати дослідження. 3 отриманих результатів випливає, що інгібіторна мережа Петрі є простішою, тобто містить меншу кількість позицій і дуг. Зокрема проста мережа Петрі для моделювання контролера збору даних автоматизованої системи обліку пасажиропотоку громадського транспорту містить 11 переходів, 14 позицій і 28 дуг, а інгібіторна - 11 переходів, 12 позицій і 25 дуг (див. рис. 4). Використання інгібіторних мереж Петрі дає змогу спростити структуру моделей на основі мереж Петрі, що в кінцевому підсумку призводить до зменшення обчислювальних ресурсів, які необхідні для реалізації цих моделей з використанням персонального комп'ютера.

Висновки. Доведено актуальність побудови автоматизованих систем обліку пасажиропотоку для оптимізації та модернізації транспортної системи "розумного" міста. Побудовано та досліджено модель контролера збору даних для автоматизованої системи обліку пасажиропотоку громадського транспорту "розумного" міста на основі інгібіторних мереж Петрі. Отримані результати дають змогу стверджувати, що використання інгібіторних мереж Петрі для моделювання роботи автоматизованої системи є значно ефективнішим у плані спрощення структури моделей та зменшення обчислювальних ресурсів персонального комп'ютера для їх побудови і дослідження.

\section{Перелік використаних джерел}

Boreiko, O. Y., Teslyuk, V. M., Zelinskyy, A., \& Berezsky, O. (2017). Development of models and means of the server part of the system for passenger traffic registration of public transport in the "smart" city. Eastern-European Journal of Enterprise Technologies, 1-2(85), 40-47.

Boreiko, O., \& Teslyuk, V. (2017a). Model of a controller for registering passenger flow of public transport for the "smart" city system. Proc. of the 14 Intern. Conf. on The Experience of Designing and Application of CAD Systems in Microelectronics, CADSM'2017, (pp. 207-209). Lviv-Polyana: Publishing House Vezha\&Co. https://doi.org/10.1109/CADSM.2017.7916116

Boreiko, O., \& Teslyuk, V. (2017b). Model of data collection controller of automated processing systems for passenger traffic public transport "smart" city based on Petri nets. Advanced Information and Communication Technologies: Proceeding of the 2nd International Conference on, (AICT'2017), IEEE, (pp. 62-65).

Byun, J. H., Kim, S. Y., Sa, J. H., Shin, Y. T., Kim, S. P., \& Kim, J. B. (2016). Smart city implementation models based on IoT (Internet of Things) technology. Proceedings of Advanced Science and Technology Letters, 129, 209-212.

Gentile, G., \& Nökel, K. (2016). Modelling Public Transport Passenger Flows in the Era of Intelligent Transport Systems. COST Action TU1004 (TransITS). Springer. $641 \mathrm{p}$.

Kotov, V. E. (1984). Petri Nets. Moscow: Science. 160 p.

Kupriyanovsky, V. P., Bulancha, S. A., Chernykh, K. Y., \& Namiot, D. E., (2016). Smart cities as the "capitals" of the digital economy. International Journal of Open Information Technologies, 2, 41-52.

Lebedeva, O. A. (2014). Sovershenstvovanie metodov monitoringa passazhiropotokov na marshrutakh gorodskogo passazhirskogo transporta obshchego polzovaniia [Perfection of methods for monitoring passenger traffic on public urban passenger transport routes]. Candidate Dissertation for Technical Sciences. Irkutsk. 171 p. [in Russian].

Nowicka, K. (2014). Smart City logistics on cloud competing model. Procedia-Social and Behavioral Sciences, 151, 266-281.

Zhuhadar, Leyla, Thrasher, Evelyn, Marklin, Scarlett, \& de Pablos, Patricia Ordóñez. (2017). The next wave of innovation - Review of smart cities intelligent operation systems. Computers in Human Behavior, 66, 273-281. https://doi.org/10.1016/j.chb.2016.09.030

О. Ю. Борейко ${ }^{1}$ В. Н. Теслюк 2

${ }^{1}$ Тернопольский начиональный экономический университет, г. Тернополь, Украина

${ }^{2}$ Национальный университет "Львовская политехника", г. Львов, Украина

\title{
ИСПОЛЬЗОВАНИЕ ИНГИБИТОРНЫХ СЕТЕЙ ПЕТРИ ДЛЯ ПОСТРОЕНИЯ АВТОМАТИЗИРОВАННОЙ СИСТЕМЫ УЧЁТА ПАССАЖИРОПОТОКА ОБЩЕСТВЕННОГО ТРАНСПОРТА "УМНОГО" ГОРОДА
}

\begin{abstract}
Определен общий тренд политических инициатив Европейского Союза по модернизации и повышении эффективности всех сфер деятельности современных мегаполисов. Проведен анализ базовых принципов концепции "умного" города, направленных на оптимизацию транспортной системы современных городов. Доказана важность исследования пассажиропотоков общественного транспорта, результаты которого могут быть использованы для разработки комплекса мер по совершенствованию организации существующих перевозок пассажиров на действующих маршрутах, а также для реорганизации транспортной сети города в целом. Осуществлен анализ средств моделирования сложных дискретных систем для построения и исследования моделей автоматизированной системы учета пассажиров в общественном транспорте "умного" города. Доказано, что использование ингибиторных сетей Петри обеспечивает более эффективный процесс моделирования, ведь для построения модели на их основе необходимо использовать меньше элементов сети, что, в свою очередь, приводит к генерации более четкого, понятного и легкого для анализа графа досягаемости состояний сети Петри. Разработана модель контроллера сбора данных о пассажиропотоке автоматизированной системы на основе ингибиторных сетей Петри. Использование ингибиторных сетей Петри позволяет упростить структуру модели, что приводит к уменьшению вычислительных ресурсов, которые необходимы для реализации модели средствами персонального компьютера.
\end{abstract}

Ключевые слова: модель; контроллер; ингибиторные дуги; транспортная система города; исследование модели.

O. Yu. Boreiko1, V. M. Teslyuk ${ }^{2}$

${ }^{1}$ Ternopil National Economic University, Ternopil, Ukraine ${ }^{2}$ Lviv Polytechnic National University, Lviv, Ukraine

\section{USE OF PETRI NETS WITH INHIBITOR ARCS TO CONSTRUCT THE AUTOMATED SYSTEM FOR REGISTERING PASSENGER FLOW IN PUBLIC TRANSPORT OF A SMART CITY}

The proposed study provides the analysis of the main directions of the smart city concept implementation. Particular attention is paid to the role of public transport of a smart city and the transport system as a whole. The basic principles of the concept of a smart city designed to optimize the transport system of modern cities were analyzed. The importance of the study of passenger flow in pub- 
lic transport was proven. The results of the study can be used to develop a set of actions to improve the organization of existing passenger traffic on operating routes. They can also be used to reorganize the transport network of the city as a whole. According to the research materials, it is possible to define the main technical and operational indicators of the operation of buses: the volume of traffic, passenger flow, average range of passengers' journeys, the load of buses and their number on routes, the duration and number of working shifts, speed, intervals and frequency of traffic, and mileage during the shift. These data can be used to improve the system of routes, and also organization of movement and the operation of buses on each specific route. A comparative analysis of the simple Petri nets and Petri nets with inhibitor arcs for the construction of an automated system for public transport passenger flow registering, was carried out. The model of data collection controller for the automated system of passenger flow registering for a smart city based on the Petri nets with inhibitor arcs, was constructed and explored. The use of inhibitory networks to build a controller model of an automated system of public transport passenger flow registering of a smart city has enabled significant reducing the number of network elements. As a result, it became possible to simplify and make the whole process of designing and researching the models more effectively. Reducing the number of elements led to the generation of a clearer, more understandable, and easier to analyze the Petri nets reachability graph. The use of Petri nets with inhibitor arcs is proved to allow simplifying the structure of the model, which reduces the computational resources needed to implement the model by means of a personal computer.

Keywords: model; controller; inhibitor arcs; transport system of a city; model research. 